\title{
PROBLEMS ON SFG THEMATIC PROGRESSION IN ESL ACADEMIC WRITING
}

\author{
Heri Kuswoyo \\ rikuyo_85@yahoo.com \\ Susardi \\ sardiyang@yahoo.com \\ Universitas Teknokrat Indonesia Bandar Lampung
}

\begin{abstract}
The objective of this research is to identify the problems on the thematic progression in fifth semester students' academic writing. It examines the problems caused by the misuse of theme and rheme in the thematic progression of their writing. The data in this research are taken from 20 pieces of fifth semester students' academic writing. The collected data are analyzed based on the theory of problem in thematic progression, regarding misuse of theme and rheme put forward by Bloor \& Bloor (1992) and Arunsirot (2013). Then, descriptive qualitative and library research methods are applied in this research. The results of the research reveal that six problems in thematic progression are found; they are the problem of brand new theme, the problem of double rheme, the problem of empty rheme, the problem of empty theme, the problem of overuse of constant theme pattern and the problem of confusing selection of textual theme. In addition, other four new problems are also identified. They are the problem of incomplete clause, the problem of error in choosing topical theme, the problem of unneeded textual theme, and the problem of double textual theme. In conclusion, the students must be aware of the flow of theme and rheme of thematic progression in their writing.
\end{abstract}

Keywords: attitudes, international students, English

\section{INTRODUCTION}

A good piece of writing must fulfill the principle of cohesion and coherence. According to Halliday \& Hasan (1976, 4), cohesion refers to the relations of meaning within a text that occurs where the interpretation of some elements in the discourse is dependent on that of another. Two elements exist in the cohesive relations, the presupposing and the presupposed, and they are integrated into a text. Meanwhile, coherence refers to the ideas that hang together in a text. It means that what has been stated before in a text provides the idea of what will be coming next (Halliday \& Hasan, $1989,48)$. It can be seen that there are two important points of cohesion and coherence, which are the elements or the forms and the ideas or the meanings.
The study of how forms and meaning are related each other is known as Systemic Functional Grammar (SFG). Based on Lock, SFG is the study that sees language first and foremost as a system of communication and analyzes grammar to discover how it is organized to allow speakers and writers to make and exchange meanings $(1996,1)$. It can be seen that SFG views the organization of the form (grammar) in meaning (semantic) perspective. Specifically, in terms of cohesion and coherence, SFG deals with the analysis of textual metafunction (the function of language to organize a text) that sees clause as message and focuses on the theme and rheme structure (thematic progression) in a text (Bloor \& Bloor, 2004,10-11; Halliday \& Matthiessen, 2014, 83; Sujatna, 2013, 383). 
Thematic progression, which contributes to the cohesion and coherence of a text, is very important especially in a piece of advanced writing that has wide range of purpose. It is because in this kind of writing, the messages that will be delivered should be really assured to be gotten by the readers. It is also because in this kind of writing, the messages that will be delivered have more effects than those of other kinds of writing. It is also because in this kind of writing, the messages that will be delivered will get more attention than those of other kinds of writing. Therefore, it can be implied in this kind of writing, the thematic progression or the flow of the theme and rheme must be organized well.

On the other hand, it cannot be denied that sometimes the writers do not pay attention to the flow of the theme and rheme of the writing. They do not take a more look on how to produce smooth ideas through the organization of the theme of the writing. They do not concern too much on how to create linked or connected thought in the writing. As the consequence, there will be the problems in the thematic progression of the writing.

In this research, the writer gets interested in analyzing the problems in thematic progression of fifth semester students' academic writing because they are written by high level students who are expected to produce good and structured academic writing. Based on this reason, the writer thinks that it is very needed to analyze the problems in the thematic progression of the writing, regarding the misuse of theme and rheme so that later, the problems can be minimized or avoided.

\section{LITERARY REVIEW}

Belmonte and McCabe-Hidalgo (1998) analyzed the thematic selection and progression of the students' compositions written by Spanish native speakers learning English as a second language. This research more focused on uncovering the problems occurring in the thematic selection and progression. The result of the research showed that there were seven problems occurring in the students' compositions, which are the problem of brand new theme, the problem of empty rheme, the problem of overuse of constant progression, the problem of confusing selection of discoursal and topical theme, the problem of intervening material between mention in rheme and subsequent thematization, the problem of overuse of there, and the problem of themes with unclear reference. Another research was done by Rakhman (2013) who examined thematic progression patterns in high school students' exposition texts based on the level of achievement. The research found the greatest use of constant theme pattern, followed by simple linear thematic progression and derived theme progression. It was also found that simple linear thematic progression and derived theme progression were frequently to occur in middle and high achievers, meanwhile constant theme pattern in low achievers. Then, Sujatna (2013) examined the thematic progression patterns in Sundanese text (short stories) which were written by Sundanese female writers. The research findings showed that $27 \%$ the Sundanese female writers use simple thematic progression and $73 \%$ use multiple thematic progressions. Further, the former one consisted of linear theme (9\%), constant rheme (9\%) and constant theme (9\%) and the latter one consisted of two element thematic progression $(36,50 \%)$, three element thematic progression $(18,25 \%)$, and four element thematic progression $(18,25 \%)$. An extended research was done by Arunsirot (2013) who elaborated thematic selection, thematic pattern, and the problems in the thematic progression in the writing of Thai EFL learners. This research findings figured 
out that in term of thematic selection, textual themes were used more than interpersonal themes and the multiple theme overweigh the simple theme. Besides, in term of thematic progression, three patterns were found in the writing, which were theme reiteration or constant theme pattern, zigzag theme pattern, and multiple theme or split rheme pattern. Further, in term of the problems in the thematic progression, there were found five problems. They were the problem of brand new theme, problem of empty rheme, problem of empty theme, the problem of overuse of constant progression, and the problem of confusing selection of textual theme. Albogobeish and Sedghi (2014) in their research explored thematic progression patterns used in the research article abstract written in English by research article writers from the Arabic Literature discipline. The result of the research showed that there were 2 thematic progression patterns used by the writers in the research article abstract, which were linear thematic progression pattern and constant thematic progression pattern. It was found that the constant thematic progression was used greater than linear thematic progression pattern. In addition, it was also found the use of miscellaneous pattern in the research article abstract.

Considering all previous studies above, the writer decides to take the discussion on thematic progression with the object which is different from them. The writer discusses the thematic progression problems in high level students' advanced writing, which is the academic writing of fifth semester students.

\section{Thematic Progression}

As stated by Eggins (2004, 324326), thematic progression is the method of development of theme and rheme. It can also be said that thematic progression is the system of how theme and rheme are developed in a clause, as
Daneš in Jing $(2015,181)$ mentioned, "Indeed, as the text unfolds, the themes connect to the themes and rhemes of preceding clauses in various ways, picking up or repeating the important concepts and developing them further, whose connections form patterns of thematic progression."

\section{Theme and Rheme}

Theme is the element that serves as the point of departure of the message. It is that which the clause is concerned or it is what the clause is about. The remainder of the message, the part in which the theme is developed, is called as rheme (Gerot \& Wignell, 1994, 103, Halliday and Matthiessen 2004, 64). This definition is added by Bloor \& Bloor (2004, 71)that defines theme as the idea represented by the constituent at the starting point of the clause and rheme as the rest of the message. The following ia an example of theme and rheme in a clause:

The duke has given my aunt that

$\begin{array}{ll}\text { My aunt } & \text { hapot } \\ \text { hasen given that teapot }\end{array}$ by the duke

That teapot the duke has given to my aunt

\section{Theme Rheme}

(Halliday \& Matthiessen 2014, 90)

From the example above, it can be seen that the duke, my aunt, and the teapot tell what the clauses are about. They are also the main point and the starting point of the message. Thus, they are the themes of the clauses. On the other hand, the remainders of the themes has given my aunt that teapot, has been given that teapot by the duke, and the duke has given to my auntare the rests of the message. They are the parts developed from the theme. Therefore, they are the rheme of the clause.

\section{Types of Theme}

Based on Gerot \& Wignell (1994, 104), theme is categorized into three different types, which are topical, textual and interpersonal themes. 


\section{Topical theme}

This kind of theme is usually the first nominal group in the clause. However, it can also be nominal group complexes, adverbial groups, prepositional phrase, or embedded clause. The topical theme that is also the subject of a clause is called as unmarked topical theme. On the other hand, the topical theme that is not the subject of the clause is called as marked topical theme. In the clause the theme is reliazed by the prepositional phrases which are acting as circumstantial Adjuncts, for example:

After the war, the Spartans erected a memorial on the battlefield of Thermopylae... (Bloor \& Bloor 2004: 76).

\section{Textual theme}

Textual theme is the theme that relates the clause to its context. They can be in the form of continuatives and/or conjunctive adjuncts and conjunctions (Gerot \& Wignell 1994, 105). Continuatives are small sets of discourse items which signal that a new move is beginning, such as yes, no, and $o h$. Conjunctive adjuncts are those which relate the clause to the preceding text, such as in other words (Halliday in Ebrahimi \& Khedri 2012, 7). The type of conjuctive adjuncts can be seen in Table 1.

In addition, conjunctions are words or groups that either links or binds the clause in which it occurs structurally and semantically to another clause (Halliday \& Matthiessen 2014, 107). What differentiate conjunctive adjuncts and conjunctions is that, while conjunctive adjuncts set up a semantic relationship with what precedes, conjunctions set up semantic and grammatical relationship - they construct the two parts into a single structural unit (Halliday 1994, 50). The types and example of conjunctions can be seen in Table 2.
Table 1: Conjunctive Adjuncts

\begin{tabular}{|c|c|c|}
\hline Type & Meaning & Example \\
\hline appositive & i.e., e.g. & $\begin{array}{l}\text { that is, in } \\
\text { other words, } \\
\text { for instance }\end{array}$ \\
\hline corrective & rather & $\begin{array}{l}\text { or rather, at } \\
\text { least, to be } \\
\text { precise }\end{array}$ \\
\hline dismissive & $\begin{array}{l}\text { in any } \\
\text { case }\end{array}$ & $\begin{array}{l}\text { in any case, } \\
\text { anyway, } \\
\text { leaving that } \\
\text { aside }\end{array}$ \\
\hline summative & in short & $\begin{array}{l}\text { briefly, to sum } \\
\text { up, in } \\
\text { conclusion }\end{array}$ \\
\hline verifactive & actually & $\begin{array}{l}\text { actually, in } \\
\text { dact, as a } \\
\text { matter of fact }\end{array}$ \\
\hline additive & and & $\begin{array}{l}\text { also, } \\
\text { moreover, in } \\
\text { addition, } \\
\text { besides }\end{array}$ \\
\hline adversative & but & $\begin{array}{l}\text { on the other } \\
\text { hand, } \\
\text { however, } \\
\text { conversely }\end{array}$ \\
\hline variative & instead & $\begin{array}{l}\text { instead, } \\
\text { alternatively }\end{array}$ \\
\hline temporal & then & $\begin{array}{l}\text { meanwhile, } \\
\text { before that, } \\
\text { later on next, } \\
\text { soon, finally }\end{array}$ \\
\hline comparative & likewise & $\begin{array}{l}\text { likewise, in } \\
\text { the same way }\end{array}$ \\
\hline causal & so & $\begin{array}{l}\text { therefore,for } \\
\text { this reason, as } \\
\text { a result, with } \\
\text { this in mind }\end{array}$ \\
\hline conditional & $\begin{array}{l}\text { (if ...) } \\
\text { then }\end{array}$ & $\begin{array}{l}\text { in that case, } \\
\text { under the } \\
\text { circumstantes, } \\
\text { otherwise }\end{array}$ \\
\hline concessive & yet & $\begin{array}{l}\text { nevertheless, } \\
\text { despite that }\end{array}$ \\
\hline respective & as so that & $\begin{array}{l}\text { in this } \\
\text { respect,as far } \\
\text { as that's } \\
\text { concerned }\end{array}$ \\
\hline
\end{tabular}

\section{Interpersonal theme}

Interpersonal elements occurring before the topical theme are also thematic. They can be in the form of modal adjuncts, vocatives, finite or Whelements (Gerot \& Wignell 1994, 107). 
Modal adjunct is the adjunct functioning to indicate some aspect of the speaker's/writer's attitude to the message or his/her comment on its relevance, reliability, interest, and so on. The examples are probably, possibly, conceivably, perhaps, maybe, indisputably, without doubt, imaginably, and surely (Bloor \& Bloor, 2004, 55). In addition, vocatives refer to the someone's addressee that can be in the form of a name or familiar address term (John, Mother) or a term of affection or insult (my dear, darling, idiot). In the case of vocatives, they will be interpersonal theme if they come before topical theme (Bloor \& Bloor 2004, 78). It is implied that when they stand alone, they will be topical theme. Further, finite element is the element that functions to express primary tense, modality, and polarity. The examples are did, does, will (primary tense), can, will, must (modality), didn't, doesn't, won't (polarity) (Halliday 1994, 75-76). Then, Wh-elements are the elements requesting for missing pieces of information in Wh-questions. The examples of Wh-elements are who, when, what, how, etc. (Halliday 1994, 45-46). In the case of Wh-elements, the elements will function as both interpersonal and topical theme (Gerot \& Wignell 1994, 107; 111).

\section{Problems in Thematic Progression}

Bloor \& Bloor in Wang (2017, 167168) mention that there are three common problems resulting from the misuse of theme and rheme, which are the problem of brand new theme, the problem of double rheme, and the problem of empty rheme. Arunsirot (2013, 170-171). adds that there are three more problems, which are the problem of empty theme, the problem of overuse of constant progression, and the problem of confusing selection of textual themes.
Tabel 2: Conjunctions

\begin{tabular}{cl}
\hline \multicolumn{1}{c}{ Type } & \multicolumn{1}{c}{ Example } \\
\hline co-ordinator & $\begin{array}{l}\text { and, or, not, either, } \\
\text { neither, but, yet, so, } \\
\text { then } \\
\text { shen, while, before, } \\
\text { after, until, because, } \\
\text { it, although, unless, } \\
\text { since, that, whether, } \\
\text { (in order) to, } \\
\text { even if, in case, } \\
\text { supposing (that), } \\
\text { assuming (that), } \\
\text { seeing (that), given } \\
\text { that, provided (that), } \\
\text { in spite of the fact, in } \\
\text { the event that, so that }\end{array}$ \\
\hline
\end{tabular}

(Halliday 1994, 50)

The problem of brand new theme

Based on Bloor \& Bloor in Wang (2007, 167), the problem of brand new theme is extremely common in the work of inexperienced writers, who put new information in theme position. It means that there will be new theme(s) that are not connected to the previous theme or rheme. The example of paragraph that has brand new theme:

Exams are the results of cramming. Most of them are tests of memories, working under pressure, not ability. Teachers would teach students exam techniques...(Wang 2007, 175).

From the example, it can be seen that the first and second clause share the same themes, which are about exam. However, in the third clause, there is a brand new theme teacher that is not related to the previous themes or rhemes.

\section{The problem of double rheme}

Bloor and Bloor in Wang $(2007,167)$ notes that this problem occurs when the sentence has two rhemes with one of the rhemes is not mentioned previously. This problem will cause confusion for the readers since one of the rhemes that has been mentioned previously will seem as not related to the remains, for example: 
It was the Ministry of Education and specialist linguists who were involved in producing the first national syllabus for English (changed from Bloor \& Bloor 2004, 80).

In the example above, it can be seen that there are two rhemes. The first one is the Ministry of Education who were involved in producing the first national syllabus for English and the second is special linguists who were involved in producing the first national syllabus for English. It can be seen that the occurrence of the second rheme will make the former one seem as not related to the remains of the rheme (who were involved in producing the first national syllabus for English).

\section{The problem of empty rheme}

Bloor \& Bloor in Wang $(2007,168)$ mentions that the problem of empty rheme is also common in students' writing, who fail to present new information in rheme position. It means that the writer puts the rheme that is not further developed. For example:

Exams are the results of cramming. Most of them are tests of memories, working under pressure, not ability. Teachers would teach students exam techniques. The heavy pressure of exams and anxiety has increased number of suicide dropouts. This has been a very serious society problem (Wang 2007, 175).

In the example above, it can be seen that the rheme in the third clause exam techniques does not provide any further information. It is not explained more what actually exam techniques are. As the consequence, it will leave empty information for the readers.

\section{The problem of empty theme}

The problem of empty theme occurs when there is no unmarked topical theme existing in the theme position of the clause. It can also be said that the clause has no subject. As the result, the clause will be grammatically wrong as well, for example: '...Second, is her language style in writing' (Arunsirot
2013, 170). In the example, it can be seen that there is only textual theme second. On the other hand, there is no unmarked topical theme (subject) in the clause. As the consequence, the clause has empty (unmarked) topical theme and is grammatically incorrect.

The problem of overuse of constant theme pattern

Arunsirot $(2013,170)$ states that this problem occurs when the writers put the same theme over several clauses. In this case, the writers tend to provide more explanation for the theme instead of developing the rheme Therefore, the rheme is not further explained. Belmonte and McCabeHidalgo (1998, 22) asserts that this problem will cause the text to be read like a list. The example of the paragraph that overuses constant progression pattern:

First of all, the Reader's Digest was written by Nudee Vanessa Race. She is an expert at mind and brain. She graduated neuroscience from Harvard University. She is smart, cheerful, and intelligent. And she is considered as a genius (Arunsirot 2013, 171).

In the example, it can be seen that the second, third, fourth, and fifth clauses share the same theme she which refers to Nudee Vanessa Race. It can also be seen that there is no further development for the rheme of the clauses. As the consequence, the paragraph seems to be like a list.

The problem of confusing selection of textual theme

According to Arunsirot (2013, 171), this problem occurs when the writers have difficulties and make a mistake in selecting textual theme, especially conjunctive adjunct/conjunction. This problem will lead to the unconnected clauses, for example:

It also gives me good and the best way to be happy in our life. The story is full of beautiful and interesting words. However, it can teach us about how to 
live and survive with the truth (Arunsirot 2013, 171).

In the example, it can be seen that the all the clauses provide the same relation of information, which is about additive relation. It happens because the clauses tell about what has been given by the story. However, in the third clause, the writer puts an inappropriate conjunctive adjunct however which shows adversative relation. In this case, the writer should put a conjunctive adjunct that shows additive relation, such as moreover or in addition.

\section{Method}

In this research, the writer applied descriptive qualitative research method. It means that the writer described the results of the analysis in the form of words, not numbers, as Perry (2005, 75) states that qualitative research is characterized by verbal description of its data. These descriptions are in line with the objectives of this study which aim to identify the problems in the thematic progression of the writing in which the results were described in words. Besides, library research method is also applied in this research to find out the information for the need of the analysis.

The data sources of this research were 20 academic writing of 20 students of STBA (The Higher School of Foreign Language) Teknokrat Bandar Lampung in literary criticism class which were chosen purposively (fifth semester students' writing). Further, the data in this research were taken from the clauses of the paragraphs in the papers. The data analyzed were focused on the background of the study section of the paper since this section consisted of more data needed. Moreover, the data analyzed consisted of 85 paragraphs and 589 clauses in total.

In collecting the data, the writer applied documentation method. There were some steps the writer applied. They are: (1) getting the writing from the lecture, (2) sorting out the writing that was not used, which is sixth semester students' writing (since all writing taken consisted of both fifth and sixth semester students' writing), (3) rearranging the background sections of the writing since they were the focus of the analysis, and (4) printed out the background sections of the writing.

In analyzing the data, the writer also applied some steps. They are: (1) reading the writing, (2) coding the clauses ("C" is used, stood for clause), (3) dividing the theme and rheme, (4) marking the problems in the thematic progression of the paragraphs, and (5) classifying the problems based on the theory.

\section{Findings AND Discussions}

Based on the analysis, it is found that all problems proposed in theoretical framework occur in students writing. Besides, other problems are identified as well. The problems found in the students' writing involve the followings.

\section{The problem of brand new theme}

The problem of brand new theme refers to the new information that is put in theme position. It also means that the theme is not connected to the previous theme or rheme. In the analysis, it is found that there are four paragraphs having this problem. The example of the paragraph can be seen below:

Poems can be written to sound beautiful, to tell a story or to share a message (C8). They can have alternative meaning (C9), they can share a feeling or experience (C10), they can express just about anything (C11). But the main difference between poetry and other forms of writing is the attention the poet pays to structure, form, tone, word choice and all of those things that create the effect the poet is trying to achieve (C12). (Paper 16, Paragraph 4, Clause 8-12)

In the paragraph above, it can be seen that the theme of clause 8 is poems and it is repeated as the themes in 
clause 9,10 , and 11 by using the pronoun they. Besides, it can also be seen that the rhemes of clause $8,9,10$, and 11 describe the functions of poems. However, it can be seen the appearance of brand new theme but the main difference between poetry and other forms of writing which is not related to the themes or rhemes of previous clauses. This theme is not correlated to the themes or rhemes of previous clauses as it describes the idea of the main difference between poetry and other forms of writing.

\section{The problem of double rheme}

The problem of double rheme occurs when the sentence has two rhemes with one of the rhemes is not mentioned previously. This problem will cause confusion since the rheme that is mentioned previously will seem as not related to the remains. In the analysis, it is found that there is only one paragraph having this problem. The paragraph can be seen below:

Harlem Renaissance is a group that consists of black people who has the same goal to share their opinion trough literary work (C39). Besides that, according to Harlem Renaissance movement black people want to change American opinion about them trough the literary work and arts that contain of satirical and critic about racial issue that happen in America (C40). The form of literary work that they share is such kind of novel, poems, play, short story etc. (C41) and those literary work show the intellectuality of black people where they have a good educational background and use the appropriate language toward their works (C42).Langston Hughes is one of the members of Harlem Renaissance movement (C43) and he wrote many kind of literary work that contain of racism issue (C44). (Paper 8, Paragraph 5, Clause 39-44)

In the paragraph above, it can be seen the occurrence of double rheme in the rheme of clause 40 , want to change American opinion about them trough the literary work and arts that contain of satirical and critic about racial issue that happen in America. It can be seen that there are two rhemes in this clause, which are want to change American opinion about them through the literary work that contain satirical and critic about racial issue that happen in America and want to change American opinion about them through arts that contain satirical and critic about racial issue that happen in America. It can be seen that the occurrence of the second rheme will make the rheme which is mentioned previously seem as not related to the remains of the rheme (literary work seems as not related to that contain satirical and critic about racial issue that happen in America).

\section{The problem of empty rheme}

The problem of empty rheme occurs when the writer fails to put new information in rheme position. In other word, the rheme is not further developed. In the analysis, it is found that there are 10 paragraphs having this problem. The example of the paragraph can be seen below:

The Little Mermaid is one of the story which was written by Hans Christian Andersen in 1837 (C10). Hans Christian Andersen, a Danish storyteller, is known for stories such as The Little Mermaid.(C11) This is the tale of a mermaid who longs to be human and win the love of a prince (C12). For this, she makes a great sacrifice and takes great risks (C13). Although Andersen's stories fall into the fairytale genre (C14), they appeal to people of all ages (C15). (Paper 15, Paragraph 3, Clause 10-15)

In the paragraph above, it can be seen the occurrence of empty rheme in clause 13 . The rheme of this clause is she makes a great sacrifice and takes great risks. This rheme is empty as it fails to present further information or it is not further developed. It is not explained what actually the great sacrifice made and great risk taken by she (The Little Mermaid) are. This rheme is not further developed through 
either the remains of the rheme or the next clause theme and rheme.

\section{The problem of empty theme}

The problem of empty theme occurs when there is no unmarked topical theme existing in the theme position of the clause. It can also be said that the clause has no subject. Therefore, the clause will be grammatically wrong as well. In the analysis, it is found that there is only one paragraph having this problem. The paragraph can be seen below:

The orientalist character inside the story A Passage To India will focuses on postcolonial approach (C1). This story describe about a group of people which is Western that stay in India as a colonizer and the Indian or Eastern as a colonize (C2). There are some evidence that argue about the colonialization between western and eastern that happen in E.M Foster's story (A Passage To India) (C3). The Colonizer (western) do kinds of bad things to the society there (C4). Even if still have the western that treats people there well, It will explain in this research (C5). (Paper 7, Paragraph 1, Clause 1-6)

In the paragraph above, it can be seen the problem of empty theme in clause 5, Even if still have the western that treats people there well, It will explain in this research. It can be seen that there is only textual theme even if (actually it must be even though) without unmarked topical theme (subject). As the consequence, this clause is also grammatically wrong.

The problem of overuse of constant theme pattern

The problem of overuse of constant theme pattern occurs when the writer puts the same theme over several clauses. In this case, the writer tends to provide more information for the themes instead of developing the rheme. Further, this problem will cause the text to be read like a list. In the analysis, it is found that there are two paragraphs having this problem. The example of the paragraph can be seen below:

... Edgar Allan Poe was born in 1809 (C13); he was developed as a writer, a poet and a literary critic (C14). $\mathrm{He}$ is acknowledged as the father of modern detective story and science fiction genre (C15). Poe is known for haunting narration (C16). Some of his famous literary works are the raven, The Fall of the House of Usher, The Tell-Tale Heart etc. (C17) His dark literary works are often associated with his tragic life (C18). He was left by his father (C19) when he was nine months (C20), and unfortunately his mother died (C21) when he was three (C22). He enrolled in University of Virginia but dropped out due to poverty (C23). Even though he was a successful writer (C24), he spent his life being alcoholic (C25). He died mysteriously in October 1849 (C26) when he was only forty years old(C27)...(Paper 6, Paragraph 1, Clause 13-27)

In the paragraph above, it can also be seen that the same theme is repeated over several clauses. It can be seen that the theme of clause 13 is Edgar Allan $P o e$ and it is repeated in clause 14 and 15 by pronoun he, in clause 16 by Poe, in clause 17 by some of his famous literary work, in clause 18 by his dark literary works, in clause 19 by pronoun he, in clause 20 by when he (when: textual theme, he: topical theme), in clause 21 by and unfortunately his mother (and: textual theme, unfortunately: interpersonal theme, and his mother: topical theme), in clause 22 by when he (when: textual theme, he = topical theme), in clause 23 by pronoun he, in clause 24 by even though he (even though: textual theme, he: topical theme), in clause 25 and 26 by pronoun $h e$, and in clause 27 by when he (when: textual theme, he: topical theme). It can be seen that there are 15 clauses share the same theme. As the result, this paragraph will be read like a list. 
The problem of confusing selection of textual theme

The problem of confusing selection of textual theme occurs when the writer has difficulties and makes a mistake in selecting textual theme, especially conjunctive adjunct/conjunction. As the result, the clauses will be unconnected. In the analysis, it is found that there are twelve paragraphs having this problem. The example of paragraph having this problem can be seen below:

The character of Teddy bear shows the braveness of a doll better than a human in the short story itself (C20). Meanwhile, the other characterswhich are humans are afraid to face the dragon (C21). However, this writing aims to portray the character building in each character of The Princess short story by BaddTeddy using the theory of A.J Greimas (C22). (Paper 20, Paragraph 6, Clause 20-22)

In the paragraph above, it can be seen the problem of confusing selection of textual theme in clause 22 . It can be seen that the relation between clause 21 and 22 is causal relation. It happens because clause 21 provides the reason why the writing aims to portray the character building in the story (clause 22 ). On the other hand, textual theme (conjunctive adjunct) however is chosen to link the clauses. This textual theme is inappropriate for it shows adversative relation. Instead, the most appropriate textual themes (conjunctive adjuncts) in this case are therefore, for this reason, as a result, or with this in mind.

\section{The problem of incomplete clause}

The problem of incomplete clause occurs because there is element that does not exist in a clause. Syntactically, a major clause must have at least subject and predicate. If one of these elements does not exist, the clause will be incomplete. Further, it may be said that it is actually not a clause. This problem will disturb the flow of theme and rheme of previous and next clauses because when a clause has only subject (which serves as topical theme) without predicate, there will be no rheme or remainder of the message in the clause. In the analysis, it is found that there are seven paragraphs whose clauses are incomplete. The example of the paragraph can be seen below:

Gods create the world with all the things that have uniquenes, such as some special features (C1) ... (C5). The dwarfs who have a life that is almost similar to humans in general, while elves that have a wide range of unique in its kind. In myths and story tales, dwarfs and elves are small humanlike creatures (C6),...(C14). (Paper 1, Paragraph 1, Clause 1-14)

In the paragraph above, it can be seen that after clause 5, there are two clauses which are incomplete. The first one is the dwarfs who have a life that is almost similar to humans in general and the second one is while elves that have a wide range of unique in its kind. These two clauses are incomplete since they consist of only subjects without predicate. As the consequence, they will cause the problem in the flow of theme and rheme of previous and next clauses since there are no rhemes or remainders of the message in the clauses.

The problem of error in choosing topical theme

Almost the same as the problem of empty theme, the problem of error in choosing topical theme also occurs when there is no subject in the clause. The difference is that, while the problem of empty theme deals with the non existence of topical theme, the problem of error in choosing topical theme deals with the writer's mistake in determining the topical theme used in a clause. In this problem, topical theme exists in the clause, but the choice is incorrect so there is no subject in the clause. In the analysis, it is found that there are five paragraphs whose topical themes are chosen inappropriately. The example of the paragraph can be seen below: 
Literary works are an expression of the human person in the form of experiences, thoughts, feelings, ideas, spirit, belief in which a form of writing that describes the life, realized in a work (C1) ... (C6). Beside that literature is very useful for readers (C7), because in literature can save and forward thinking, feeling, imagination and conditions as well as the situations that have occurred in certain areas that experienced by the authors to be conveyed to the reader (C8)... (C9). (Paper 3, Paragraph 1, Clause 1-9)

In the paragraph above, it can be seen that the writer makes a mistake in determining topical theme in clause 8 . The theme of this clause is because in literature in which because is textual theme and in literature is topical theme. Topical theme in literature is incorrect since it is a prepositional phrase which syntactically cannot serve as subject in a clause. So, this topical theme cannot be used. Instead, the appropriate topical theme is literature which is a noun group which can syntactically serve as a subject in a clause.

\section{The problem of unneeded textual theme}

The problem of unneeded textual theme occurs when the writers put unnecessary textual theme, especially conjunctive adjunct or conjunction, in a clause. It means that the textual theme is actually not needed to put, but the writers put it. In the analysis, it is found that there are four paragraphs whose clauses have unneeded textual theme. The example of the paragraph can be seen below:

In this paper, the writer will explain about the orientalism theory inside the story according to Edward W Said (C7). Orientalism is the way of thinking which is based on the difference of ontology from epistemology who created between Eastern (The Orient) and Western (The Occident) (C8). In this story A Passage To India describing about the colonization that coming from the European who do discrimination toward The Indian (C9), and then The European used to make European cultural entity more supreme rather than The Indian (C10). That is why, the writer choose this story (C11) because the writer think if colonization in this story very visible (C12). (Paper 7, Paragraph 2, Clause 7-12)

In the paragraph above, it can be seen that in clause 12, textual theme (conjunction) because is used. In this clause, this conjunction is actually not needed to put. Conjunction because is used to show causal relation. Meanwhile, it can be seen that in clause 11, the expression that is why has shown causal relation. It has shown the reason why the writer chooses the story to analyze. Therefore, the conjunction because in clause 12 should be ommited. To make it correct, the writer can separate clause 11 and 12, meaning that the writer can make clause 11 as a single clause (or end it with full stop). Then, in clause 12 , the writer can start the clause by directly using topical theme the writer, without textual theme because.

\section{The problem of double textual theme}

The problem of double textual theme occurs when the writers inappropriately put textual themes, especially conjunctions, in two adjacent clauses. As the consequence, the clauses will be syntactically wrong. Besides, the clauses will also have a redundant conjunction. In the analysis, it is found that there are four paragraphs whose clauses have double textual theme. The example of the paragraph can be seen below:

Literature is what makes the world whirl (C1). By reading literature with a critical eye, one can begin to go beyond simply expressing a like or dislike of a particular text (C2), that is what is called as literary criticism (C3). Then, literary criticism enables people and critics to develop an informed opinion about the meaning of a literary work (C4). Delving or finding out the deeper things into the particular view of the world that an author wanted to convey. Because every literary work must have their own style, intention and theory from 
the author (C5), so that every person or critic must have their own things to criticize or to express the judgement as well (C6). Critics may have interpretation in literary work by looking in the side of the background of the story - the relations between the literary story with the background of the author itself, and also may have judgement on the side of structure of literary work then points to the approach of structuralism (C7). (Paper 12, Paragraph 1, Clause 1-7)

In the paragraph above, it can be seen the problem of double textual theme in clause 5 and 6 . It can be seen that clause 5 is started by conjunction because and clause 6 by conjunction so that. Syntactically, this construction is wrong. It happens because only either one of the conjunctions is needed to put in the clauses. It can be seen that conjunction because in clause 5 has explained the reason for the occurrence of clause 6 so that conjunction so that in clause 6 that explains the consequence from the occurrence of clause 5 is not needed. In the same way, it can also be said the conjunction so that in clause 6 has explained the consequence from the occurrence of clause 5 so that conjunction because in clause 5that explains the reason for the occurrence of clause 6 is not needed.

To make it correct, the writer can omit one of the conjunctions so that there will be two choices of the clauses construction. The first choice is that the writer starts clause 5 by conjunction because and omits the conjunction so that in clause 6 and the second choice is that the writer omits the conjunction because in clause 5and uses the conjunction so that in clause 6 (by firstly eliminating comma before the conjunction so that).

\section{Conclusion}

Based on the result of the analysis, it can be seen that all problems in thematic progression proposed in the theoretical framework occur in student's writing. Besides, other four new problems occur in the students' academic writing. These findings are more than those of the studies by Belmonte and McCabe-Hidalgo (1998) showing seven problems occurring in the text and by Arunsirot (2013) showing five problems occurring in the text. Therefore, it can be concluded that the students must be aware of the flow of theme and rheme of thematic progression in their writing. Thus, they can produce a good writing with the principle of cohesion and coherence.

\section{REFERENCES}

Alboghobeish, Abdol Karim \& Hamed Sedghi. 2014. "Information Development in Arabic Research Article Abstract". International Journal of English and Education. 3: 42-49

Arunsirot, Sudrutai. 2013. "An Analysis of Textual Metafunction in Thai EFL Students' Writing”. Novitas-ROYAL, 7(2): 160-174

Belmonte, Isabel Alonso \& Anne McCabeHidalgo. 1998. "Theme-Rheme Pattern in L2 Writing". Didáctica. 10: 13-31.

Bloor, Thomas \& Meriel Bloor. 1992. "Given and New Information in the Thematic Organization of Text: An Application to the Teaching of Academic Writing". Occasional Paper in Systemic Linguistics. 6: 33-43

Bloor, Thomas \& Meriel Bloor. 2004. The Functional Analysis of English. London: Arnold

Ebrahimi, Seyed Foad \& Mohsen Khedri. 2012. "The Importance of Thematic Structure in Students' Writing Cohesion”. Language in India.12: 64-78

Eggins, Suzanne. 2004. An Introduction to Systemic Functional Linguistics. London: Continuum

Gerot, Linda \& Peter Wignell. 1994. Making Sense of Functional Grammar. Cammaeray: GerdStabler Antipodean Educational Enterprises

Halliday, MAK. 1994. An Introduction to Functional Grammar Second Edition. London: Edward Arnold

Halliday, MAK \& Christian MIM. Matthiessen. 2004. An Introduction to 
Functional Grammar Third Edition. London: Arnold

Halliday, MAK. \& Christian MIM. Matthiessen. 2014. Halliday's Introduction to Functional Grammar Fourth Edition. Abingdon: Routledge

Halliday, MAK \& Ruqaiya Hasan. 1976. Cohesion in English. London: Longman Group

Halliday, MAK and Ruqaiya Hasan. 1989. Language, Context, and Text: Aspects of Language in a Social-Semiotic Perspective. Oxford: Oxford University Press

Jing, Wei. 2015. "Theme and Thematic Progression in English Writing Teaching". Journal of Education and Practice. 6: 178-187

Lock, Graham. 1996. Functional English Grammar. Cambridge: Cambridge University Press
Perry, Fred L. 2008. Research in Applied Linguistics: Becoming a Discerning Consumer. New Jersey: Laurence Erlbaum Associates

Rakhman, Asri Nur. 2013. "An Analysis of Thematic Progression in High School Students Exposition Texts". Passage. 1 (1): 65-74

Sujatna, Eva Tuckyta Sari. 2013. "Thematic Progression of Sundanese Female Writers". International Journal of Language Learning and Applied Linguistics Worlds (IJLLALW), 4 (4): 382-389

Wang, Lixia. 2007. "Theme and Rheme in the Thematic Organization of Text: Implications for Teaching Academic Writing”. Asian EFL Journal. 9 (1):164176 